\title{
Asthma control in primary care in Sweden: a comparison between 2001 and 2005
}

\author{
*Björn Ställberg ${ }^{a}$, Karin Lisspers ${ }^{a}$, Mikael Hasselgren ${ }^{a}$, Christer Janson ${ }^{b}$, \\ Gunnar Johansson ${ }^{a}$, Kurt Svärdsudda \\ a Department of Public Health and Caring Sciences - Family Medicine and Clinical Epidemiology, Uppsala University Science Park, Sweden \\ b Department of Medical Sciences, Respiratory Medicine and Allergology, Uppsala University, Sweden
}

Received 15th July 2008; revised 29th December 2008; accepted 31st January 2009; online 19th May 2009

\begin{abstract}
Aim: To compare the degree of asthma control in 2001 and 2005 in a primary care setting in Sweden.

Method: Two similar questionnaire surveys were performed in 2001 and 2005 with 1,012 and 224 asthma patients aged 18-45 randomly selected from 42 and 56 primary health care centres, respectively. A classification of asthma control similar to the GINA guidelines was made using information obtained from the questionnaire.

Results: In 2001, 36.6\% had achieved asthma control, 23.8\% were partly controlled and 39.6\% uncontrolled. In 2005, the corresponding figures were $40.2 \%, 26.8 \%$ and $33.0 \%$, respectively, with no difference between the two surveys ( $p=0.114)$. Uncontrolled asthma was more common in women $(p<0.001$ in the first and $p<0.05$ in the second survey) and smokers $(p<0.01$ in the first and $p<0.01$ in the second survey). The use of combination corticosteroid/long-acting bronchodilator inhalers had increased $-34.2 \%$ and $48.2 \%$, respectively $(p<0.001)$ - and many patients used their inhaled corticosteroids periodically.

Conclusion: In spite of treatment guidelines many patients in Swedish primary care still have insufficient asthma control.

(C) 2009 General Practice Airways Group. All rights reserved.

B Ställberg et al. Prim Care Resp J 2009; 18(4): 279-286

doi:10.4104/pcrj.2009.00024
\end{abstract}

Keywords asthma, primary care, asthma control, GINA guideline, Sweden, questionnaire surveys

\section{Introduction}

Asthma is a common chronic disease, affecting daily activities in many patients. Several studies have demonstrated that a substantial number of asthma patients do not achieve treatment goals as specified in international guidelines. ${ }^{1-3}$

The Global Initiative for Asthma (GINA) is an internationally-accepted guideline with proposed goals for asthma treatment and management. ${ }^{4}$ Until 2005, disease severity was separated into four levels, but in the more recent guideline an assessment of asthma control is recommended. ${ }^{4,5}$ The degree of asthma control is divided into three levels "controlled", "partly controlled" and "uncontrolled". The aim of asthma treatment should be to achieve complete control, characterised by no daytime symptoms or need for reliever (twice or less per week), no limitations of activities, no nocturnal symptoms, no exacerbations and normal lung function.

Most studies of asthma control have been populationbased and have included patients treated both in primary and secondary care. ${ }^{1,2,6,7}$ Some studies, performed entirely in primary care, have demonstrated the same lack of asthma control as in the population-based studies. ${ }^{8,9}$ In Sweden, as well as in several other countries, the majority of adolescents and adults with asthma are treated in primary care. ${ }^{10}$

It is also important to evaluate possible changes in asthma control over periods of time, but to our knowledge no such study has been published with data on randomly selected patients managed in primary care. The aim of this study, therefore, was to compare the extent of asthma control in two cross-sectional surveys performed in 2001 and 2005 in a primary care setting in Sweden.

\footnotetext{
* Corresponding author: Dr Björn Ställberg, Department of Public Health and Caring Sciences - Family Medicine and Clinical Epidemiology, Uppsala University, Science Park, 75185 Uppsala, Sweden. Tel:+46 703149944 Fax: +4615653533 E-mail: b.stallberg@salem.mail.telia.com
} 


\section{Methods}

\section{Sampling}

In the first survey in 2001, the organisation of asthma care at primary health care centres (PHCCs) in mid-Sweden was investigated. ${ }^{11}$ Of the 238 PHCCs, the smallest ones were excluded (PHCCs with catchment areas with fewer than 3,000 inhabitants) and the remaining 193 were stratified into three groups according to their organisation of asthma clinics. From these strata, a proportional random sample of 42 PHCCs was drawn. ${ }^{12}$

Each of the 42 PHCCs generated a list of all patients with an asthma diagnosis who attended the PHCC because of asthma at least once during the previous 18 months. From these lists, samples of patients in the age range 15-45 years were drawn. From lists containing 40 or fewer, all patients were sampled, while from longer lists a random sample of 40 patients was drawn, generating a total of 1,477 patients.

In the second survey in 2005, 56 PHCCs were randomly sampled from the same geographic region as in 2001. PHCCs with catchment areas with fewer than 3,000 inhabitants were excluded, as well as three PHCCs that declined to participate. Each PHCC generated a list of all patients with an asthma diagnosis attending the PHCC during the previous four years. From these lists, random samples of 22 patients in the age range 18-75 years were drawn. At a few PHCCs with fewer than 22 patients, all patients were sampled, generating a total of 1,221 patients.

In order to have comparable groups in the two surveys, only patients aged 18-45 who had attended their PHCC because of asthma at least once during the previous 18 months were included in the 2005 survey. A total of $69 \%$ of the responders in this age group could be included.

\section{Data collection}

A questionnaire was mailed to the patients with two reminders when necessary. In the 2001 survey questionnaire, returned by a total of $77 \%$ of the patients, information was sought on demographics, asthma medication, symptoms, allergy, emergency consultations, smoking habits, and sick leave. Other questions concerned the use of $\beta_{2}$-agonists as rescue medication, night awakenings, emergency consultations, and use of oral steroids, i.e. the attainment of treatment goals. An abbreviated English version of the first questionnaire has previously been published. ${ }^{13}$

The 2005 survey questionnaire, returned by a total of $60 \%$ of the patients in the 18-45 year age group, posed the same questions about demographics, asthma medication, symptoms, emergency consultations, use of oral steroids, smoking, and sick leave. There were also questions about height, weight and the severity level of asthma as assessed by the patient.

A simplified version of the definition of asthma control with three levels - controlled, partly controlled and uncontrolled - was constructed, similar to the definition in the 2006 GINA guideline. The definitions of the levels of asthma control used in this study are shown in Figure 1. The main difference from the GINA guidelines was the lack of lung function data.

Both surveys were performed during the winter season, and both questionnaires contained the same questions about asthma control.

A telephone interview was performed in the 2001 survey with 104 non-responders (27\% of the non-responders), and $70(67 \%)$ agreed to be interviewed. In these interviews an abbreviated form of the questionnaire was used. In addition, some variables such as age and sex were known for $90 \%$ of the 104 non-responders. There was no telephone interview with non-responders in the 2005 survey but the age and sex of all non-responders was known.

Figure 1. Criteria for asthma control. The criteria are based on the definition of asthma control in GINA 2006.

\begin{tabular}{|c|c|c|c|c|c|}
\hline Characteristic & Controlled & Partly controlle & & Uncontrolled ${ }^{1}$ & \\
\hline $\begin{array}{l}\text { Night awakening due } \\
\text { to asthma symptoms }\end{array}$ & None & $\begin{array}{l}\text { One or more } \\
\text { nights last week }\end{array}$ & \multirow{2}{*}{$\begin{array}{l}\text { One of } \\
\text { these } \\
\text { present } \\
\text { last } \\
\text { week }\end{array}$} & $\begin{array}{l}\text { One or more } \\
\text { nights last week }\end{array}$ & \multirow{2}{*}{$\begin{array}{l}\text { Both } \\
\text { present } \\
\text { last } \\
\text { week }\end{array}$} \\
\hline Need for reliever & Twice or less last week & $\begin{array}{l}\text { Three times or } \\
\text { more last week }\end{array}$ & & $\begin{array}{l}\text { Three times or } \\
\text { more last week }\end{array}$ & \\
\hline Exacerbations $^{2}$ & None & \multicolumn{2}{|l|}{ None } & \multicolumn{2}{|c|}{$\begin{array}{l}\text { One or more } \\
\text { exacerbations last six } \\
\text { months }^{2}\end{array}$} \\
\hline
\end{tabular}




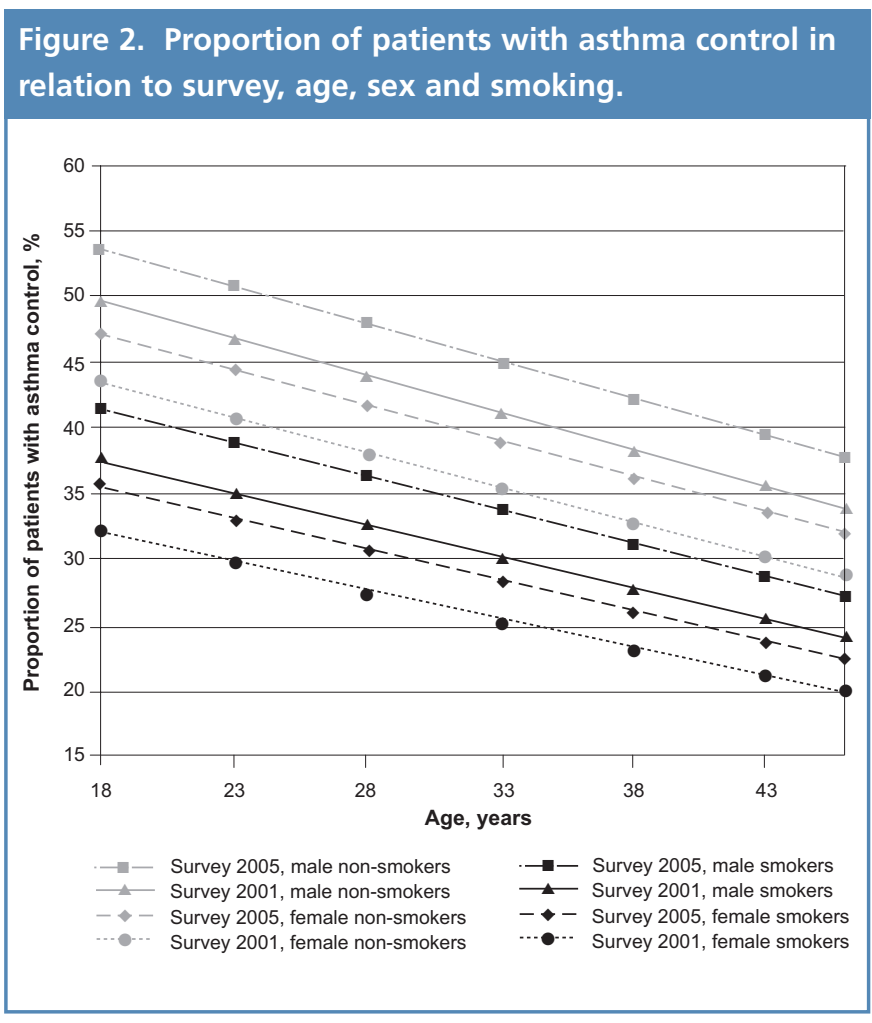

The Research Ethics Board at Uppsala University, Sweden approved both studies.

\section{Statistics}

Data were analysed with the SPSS (version 13.0) and SAS (version 9.1) statistical programme packages. The overall partial non-response proportion (missing data in returned questionnaires) was $<0.15 \%$ with a specific variable maximum of $2 \%$. Summary statistics such as means, proportions and measures of dispersion were computed using standard parametric methods. Simple differences between groups in continuous data were tested with Student's t-test or analysis of variance, and differences in proportions with the chi-square test. Multiple logistic regression was used for analyses of variables influencing asthma control, which also provided odds ratios and their 95\% confidence intervals (CI). Linear regression was used to compute adjusted mean scores. The analysis model, shown in Figure 2, was visualised by means of logistic regression technique. P-values $<0.05$ were considered as indicating statistical significance. With the sample size used in this study a difference between the two surveys in controlled asthma with $10 \%$ would be statistically significant with a power of $80 \%$.

\section{Results}

\section{Characteristics of the study population}

Patient characteristics for the two surveys are presented in Table 1. Women were in the majority in both surveys. The total mean age in each respective survey was 32.3 (SD 8.3) and 32.4 years (SD 8.2), with no differences in distribution according to sex and age between the surveys.

\section{Medication}

Short-acting $\beta_{2}$-agonists (SABA) as as-needed monotherapy were used by about a quarter of the patients in both surveys (Table 1). The proportion of patients who used inhaled corticosteroids (ICS) without addition of long-acting $\beta_{2}$ agonists (LABA) or leukotriene antagonists (LTRA) had decreased between the first and the second survey $-42.5 \%$ and $26.3 \%$, respectively $(p<0.001)$ - while the proportion of patients using ICS and LABA, or ICS and LTRA, or a combination of all three, had increased $-34.2 \%$ and $48.2 \%$, respectively $(p<0.001)$. Inhalers with fixed combinations of ICS and LABA were less frequent in 2001 than in $2005-11 \%$ and $30 \%$, respectively $(p<0.001)$.

Of the patients taking ICS as a single treatment, 54\% in the 2001 survey and $46 \%$ in the 2005 survey used their medication only periodically. In the sub-group of patients using ICS-only periodically, $69 \%$ and $58 \%$, respectively, did not achieve asthma control.

Apart from one patient in the first survey who used LTRA as monotherapy, LTRA was used as an add-on treatment by $5 \%$ and $8 \%$ in each respective survey.

\section{Asthma control}

Approximately $40 \%$ of the patients had achieved asthma control in both surveys, with no difference between the two surveys (Table 2). There was no difference in the distribution of the levels of asthma control between the two surveys, either in total or with respect to sex.

In both surveys there was a significant difference in asthma control between women and men, with more frequent uncontrolled asthma among women $(p<0.001$ in the first and $p<0.05$ in the second survey). Uncontrolled asthma was also more common among daily smokers versus nonsmokers in both the first $(50 \%$ versus $38 \%, p<0.01)$ and second surveys ( $58 \%$ versus $30 \%, p<0.01)$.

Half of the patients with combination therapy (separate inhalers or fixed combination) had uncontrolled asthma in both surveys.

Patients with controlled, partly controlled and uncontrolled asthma in the first survey had been on sick leave during the last six months in $8 \%, 15 \%$ and $41 \%$ of cases, respectively, $(p<0.001)$ while in the second survey the corresponding figures were $7 \%, 7 \%$ and $39 \%$, respectively $(p<0.001)$. There was no difference in sick leave between the two surveys.

\section{Factors influencing asthma control}

Age, sex and smoking had a significant influence on the degree of asthma control (Table 3). The combined effects of age, sex and smoking in both surveys are presented in Figure 2. The proportion of asthma control ranged from $20 \%$ to 
B Ställberg et al.

Table 1. Patient characteristics and asthma medication during the last six months in the first survey, 2001, and in the second survey, 2005. P-values refer to differences between all patients in the first and in the second surveys, respectively.

Survey 2001

Survey 2005

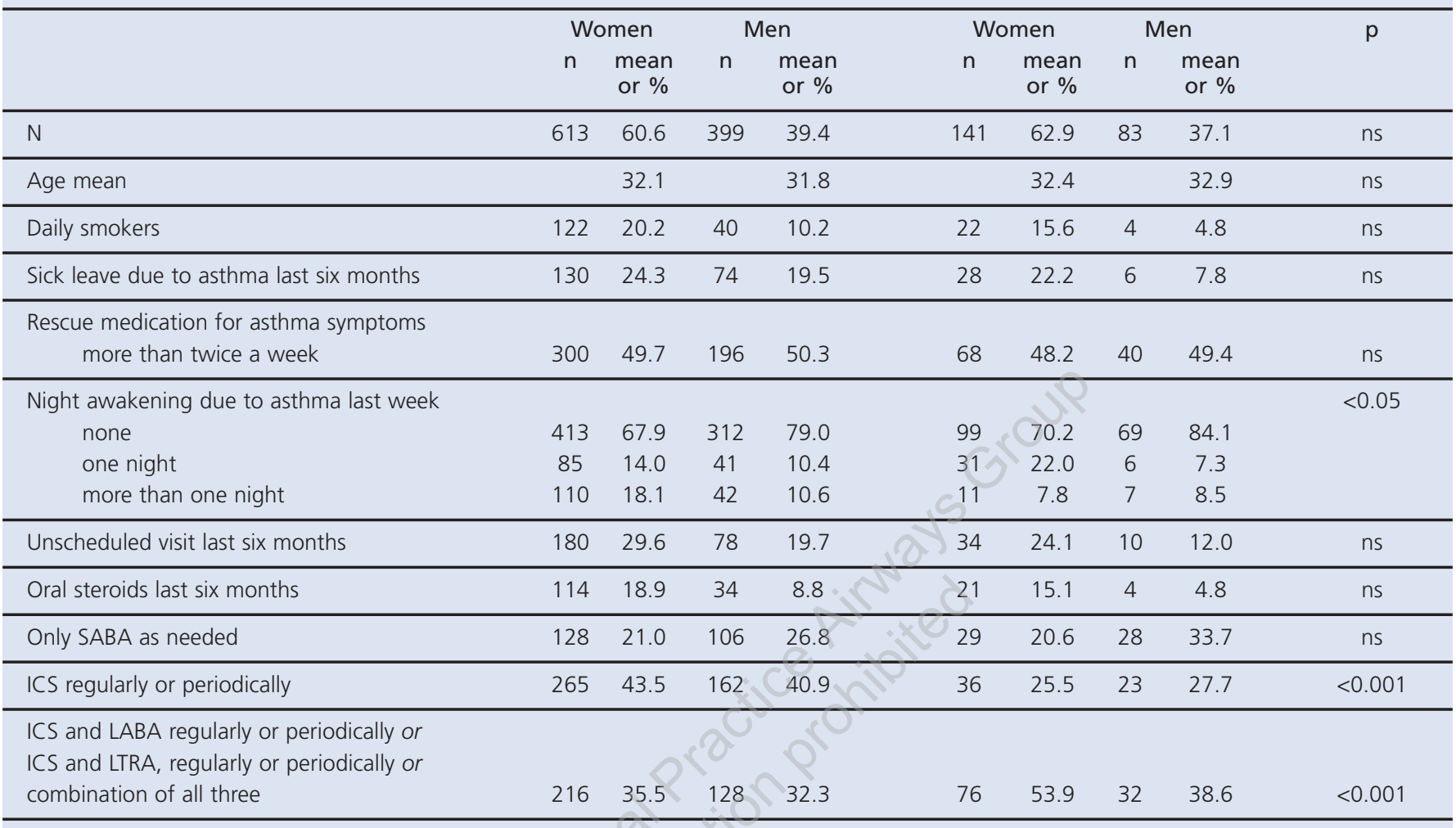

SABA = short-acting $\beta_{2}$-agonist, LABA = long-acting $\beta_{2}$-agonist, ICS = inhaled corticosteroids, LTRA = leukotriene receptor antagonists.

Table 2. Asthma control in relation to asthma treatment in the first survey, 2001, and in the second survey, 2005. P-values refer to differences in asthma control between the two surveys.

Survey $2001\left(n=1,005^{*}\right)$

Survey $2005(n=224 *)$

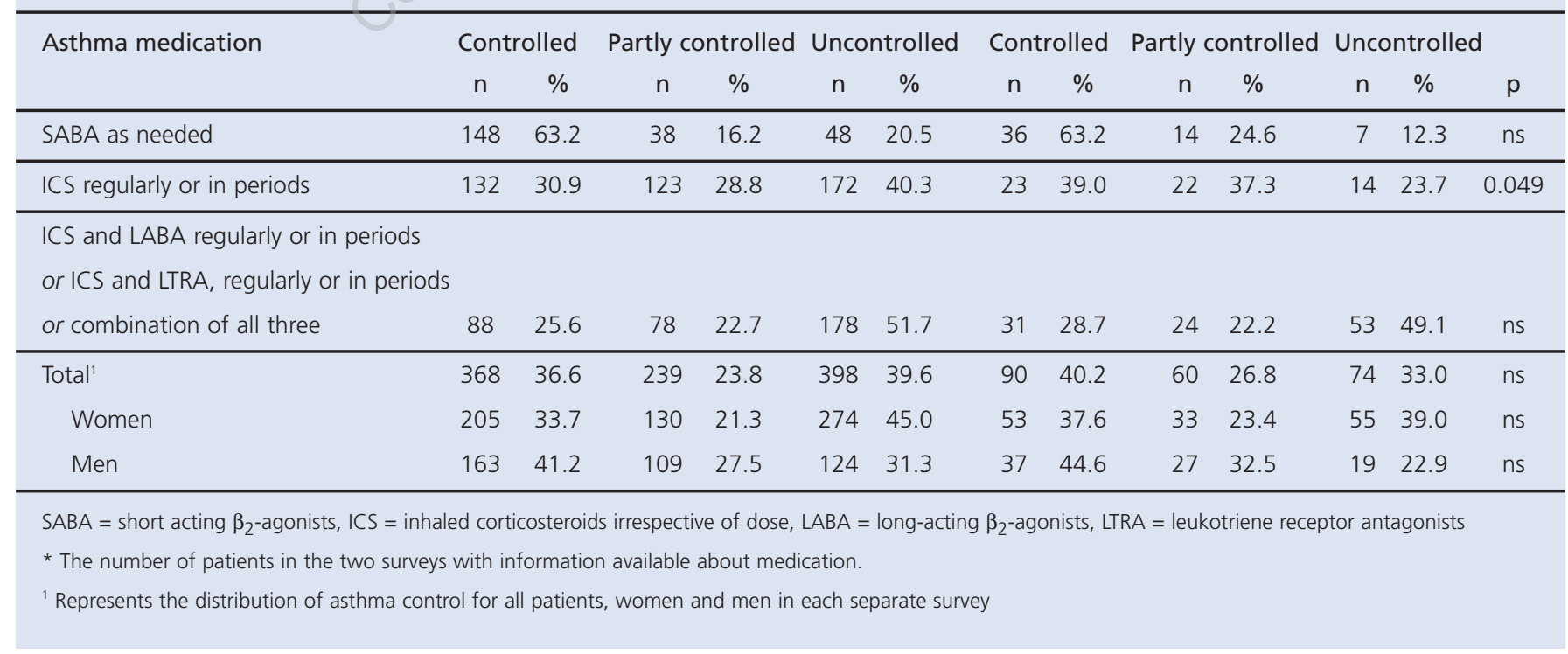




Table 3. The odds ratio (OR) for having controlled
asthma compared with partly controlled/uncontrolled
asthma adjusted for age, sex, smoking and survey with
95\% confidence intervals.
\begin{tabular}{lcc}
\multicolumn{2}{c}{ OR for controlled asthma } \\
\hline Age (increasing age) & $0.98(0.96-0.99)$ \\
\hline Sex & female & $1.28(1.01-1.63)$ \\
& 1.0 \\
\hline Daily smoker & no & $1.62(1.14-2.31)$ \\
& yes & 1.0 \\
\hline Survey & 2005 & $1.16(0.87-1.58)$ \\
2001 & 1.0
\end{tabular}

$53 \%$, depending on these factors. In both surveys, young non-smoking men were most likely to have controlled asthma. The likelihood of having uncontrolled asthma was greatest for older, smoking women.

Body mass index (BMI) was higher for patients with uncontrolled asthma than for patients with controlled and partly controlled asthma, (mean (SD) 27.2 (5.8) vs. 25.5 (4.4) $\left.\mathrm{kg} / \mathrm{m}^{2}(\mathrm{p}<0.05)\right)$. Data were only available in the 2005 survey.

Uncontrolled asthma was more common among patients with reported allergy to both pollen and pets as compared with allergy to either or no reported allergy at all, 47\%, 33\%,

Figure 3. Venn diagram demonstrating the overlap between rescue medication more than twice last week, night awakenings last week and any exacerbation last six months in patients with partly or uncontrolled asthma. The percentage in the venn diagram represents the first survey $2001(n=637) /$ the second survey 2005 $(n=134)$.

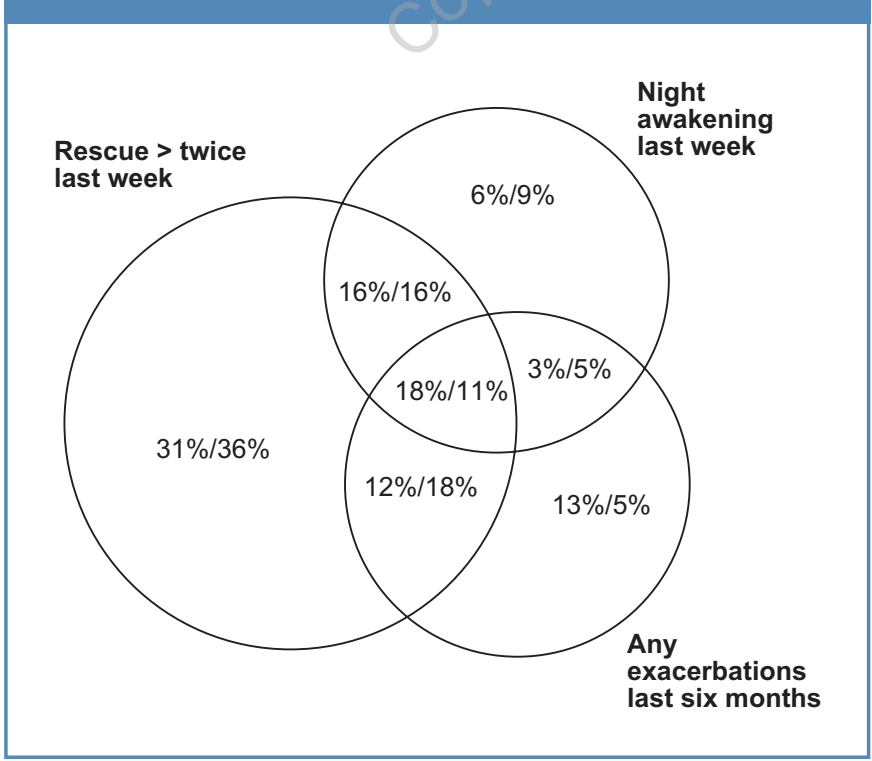

$26 \%$ and $38 \%$, respectively $(p<0.001)$, data only available in the first survey.

The distribution of different criteria for evaluating asthma control among patients with partly controlled or uncontrolled asthma is demonstrated in a Venn diagram (Figure 3). Many patients with one or more exacerbation during the last six months also had frequent use of rescue medication or night awakenings during the last week.

\section{Disease severity according to patients}

The patients in the second survey also assessed their own disease severity. Figure 4 compares this self-assessment with objective asthma control according to guidelines. Among patients with controlled asthma most patients assessed their asthma as very mild or mild, while $12 \%$ considered their asthma as moderate or severe/very severe. Most patients with uncontrolled asthma assessed their disease as moderate or severe/very severe, while $33 \%$ assessed their asthma as mild and $6 \%$ as very mild.

Twelve per cent of the patients using only SABA as needed, $24 \%$ of the patients using ICS, and $50 \%$ using a combination of ICS and LABA/LTRA, assessed their asthma as moderate, severe or very severe. There was no difference between men and women.

\section{Discussion}

This study, a comparison between two surveys performed in 2001 and 2005, demonstrates that many patients with asthma treated in primary care do not achieve asthma control, and there were no major differences between the

Figure 4. Patient self-assessed disease severity in relation to asthma control according to guidelines (data from the survey 2005).

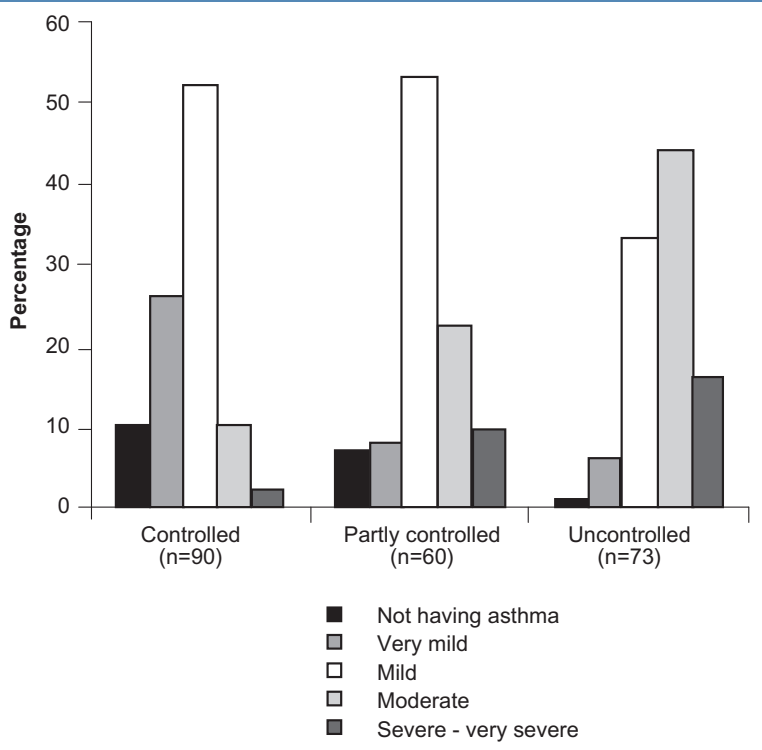


two surveys. Many patients used their ICS periodically which (probably) was not how it was prescribed. The use of combination treatment had increased during the four years, but without significant improvement in asthma control. There was also a discrepancy between the patients' own assessments of their asthma control and disease control according to guidelines.

The high prevalence of patients without controlled asthma in our study has also been demonstrated in other international studies. Over the last few years many guidelines have highlighted the importance of achieving asthma control, whilst a large number of studies have pointed out the difficulties in achieving this level of control. . $3,3,7,9^{2}$ The implementation of new guidelines in primary care is a challenge. ${ }^{14}$ Other authors have pointed out the need for effective tools for identifying poor control. ${ }^{15-18}$

More patients were treated with ICS/LABA combination inhalers in 2005 than in 2001. This may be attributable to the change in treatment guidelines, which now recommend adding LABA to ICS instead of increasing the dose of ICS. A change in prescription habits in Sweden towards the use of more fixed combination devices has also been noted. ${ }^{19}$ However, there were still a substantial number of patients with uncontrolled asthma in both surveys.

In our study, as well as in other studies, ${ }^{2}$ many patients with insufficient control only use SABA as needed, or only ICS. Many of these patients should probably be at a higher treatment level according to current guidelines. Another reason for insufficient control might be lack of adherence to prescribed medication. ${ }^{20-23}$

In our surveys we found that many patients used their ICS periodically, in contrast to treatment guidelines and (probably) in contrast to their doctor's prescription. This conceivable under-treatment might also be a contributory cause of insufficient control. Patients with uncontrolled asthma had been on more sick leave, which is of importance in terms of the economics of public health.

The Venn diagram in this report demonstrates that a high proportion of patients with exacerbations frequently use rescue medication and have night awakenings outside the exacerbation period. This may indicate that past exacerbations have not led to an adjustment in asthma management since many patients still have symptoms and need of rescue medication.

In our surveys, $37 \%$ and $40 \%$, respectively, had achieved asthma control. This can be compared to the levels of control achieved with treatment for other chronic diseases in primary care. In a 2001 study of diabetes mellitus patients in primary care in Sweden, 57\% achieved target levels of $\mathrm{HbA}_{1 \mathrm{C}} .^{24}$ In another study, 55\% of the patients treated with statins reached their goal for total cholesterol. ${ }^{25}$ It seems more difficult to achieve the goals in asthma treatment. One reason for this difference might be that the goals in asthma treatment are more complex to define and need a structured patient consultation, as compared with diseases where treatment goals are defined in terms of laboratory parameters.

The number of smokers decreased between the two surveys, but more women than men still smoked. This decrease is in accordance with the national trend in Sweden. ${ }^{26}$ Smoking has been demonstrated to have a negative influence on the effects of ICS in asthmatics and on the severity of disease. ${ }^{27,28}$ This might be one reason why fewer smokers than non-smokers achieved asthma control in our study. Women also achieved asthma control less often, which is in accordance with other studies. ${ }^{29-31}$

There was also a discrepancy between patients' own assessments of disease severity and disease control according to guidelines. Many patients in this study (as well as in other studies $^{32,33}$ ) perceived their asthma as being mild, in spite of insufficient guideline-defined disease control. On the other hand, there are patients whose asthma is controlled but who judge their own asthma to be moderate or severe. One reason for this discrepancy might be that patients have different treatment goals from those defined in guidelines. Another reason may be that our definitions of control don't take into account all limitations in daily life - limitations which are important to the individual patient when judging his/her own asthma. ${ }^{34}$

There are several strengths in this study. Both surveys included randomly sampled asthma patients from randomly sampled PHCCs in the same region in mid-Sweden. The patients were in the same age group and had made visits to the primary care centres during the last 18 months in both surveys. Both surveys were performed during the winter season, and the questionnaires contained the same questions about asthma control. Furthermore, the response rates in both surveys were satisfactory. In the 2001 survey the nonresponse telephone follow-up did not reveal any difference between responders and non-responders. ${ }^{12}$ No follow-up of the non-responders was performed in the second survey. However, as the survey was carried out with the same design and in the same region as the first survey and there were no differences according to sex or age between responders and non-responders, it is anticipated that the non-responders did not differ from the responders in any crucial manner.

The questionnaire used in these two surveys was constructed some years before the definitions of asthma control were published in the latest GINA guideline ${ }^{4}$ and consequently the classification of asthma control in this report is slightly modified in comparison with that used in the GINA guideline. However, in our opinion the definitions used in this 


\section{Discussion summary}

\section{a) Difficulties in this study}

The time interval of four years between the two surveys might be too short to measure any improvements in asthma control.

\section{b) Alternative methodologies}

It could have been beneficial to perform a clinical examination when assessing the level of asthma control.

\section{c) New questions arising}

How could the implementation of guidelines be improved in primary care?

\section{d) Lessons for clinical practice}

Many patients in primary care have insufficient asthma control. Evaluating the degree of asthma control is essential when monitoring individual patients with asthma.

report are still comparable to those in the GINA guideline.

One limitation of this study is that the results were entirely based on patient questionnaires and did not include clinical examinations or lung function tests. However, the majority of general practitioners (GPs) do not normally perform spirometry regularly on asthma patients in order to evaluate asthma control, and therefore the level of control is based only on clinical data in most cases. Another limitation of this study could be that the time interval of four years between our two surveys might be too short to measure any improvements in the management of asthma in primary care.

In Swedish primary care, each patient consulting a physician receives a diagnosis which is listed in a special register at the clinic. The patients selected from these registers, in both surveys, had consulted their GP at least once during the last 18 months. As many patients with intermittent and very mild asthma seldom seek health care, this might be an explanation for the low proportion of patients with good asthma control in this report. Also, those with mild disease might also receive medication without a physician appointment, and might then not be found in the diagnosis register for the selected period.

In spite of treatment recommendations and effective asthma medications, many patients in primary care still have insufficient asthma control. Many factors contribute to the level of control, as has been demonstrated in this study. The importance of evaluating the degree of asthma control when monitoring individual patients cannot be emphasised enough.

\section{Conflict of interest}

Björn Ställberg has been paid for lectures and for consulting from AstraZeneca, GlaxoSmithKline, Merck Sharp \& Dohme and Schering Plough.

Karin Lisspers has been paid for lectures and for consulting from AstraZeneca, GlaxoSmithKline, Merck Sharp \& Dohme and Schering Plough.

Mikael Hasselgren has no conflicts of interest.
Gunnar Johansson has received fees for consulting and for speaking at symposia arranged by AstraZeneca, GlaxoSmithKline, MSD and Schering Plough.

Christer Janson has received research grants from GlaxoSmithKline and has received fees for lectures by AstraZeneca, GlaxoSmithKline, Merck Sharp and Dohme, Boehringer Ingelheim and Pfizer.

Kurt Svärdsudd has no conflicts of interest.

\section{Acknowledgements}

The study was supported by grants from the county councils of the Uppsala-Örebro Health Care Region, The Centre for Clinical Research, Sormland, The Swedish Heart and Lung Foundation, The Swedish Asthma and Allergy Association, The Swedish Heart and Lung Association, The Bror Hjerpstedt Foundation, Uppsala, and Uppsala University. We thank all the participating centres.

\section{References}

1. Rabe KF, Vermeire PA, Soriano JB, Maier WC. Clinical management of asthma in 1999: the Asthma Insights and Reality in Europe (AIRE) study. Eur Respir J 2000;16:802-07. http://dx.doi.org/10.1183/09031936.00.16580200

2. Cazzoletti L, Marcon A, Janson C, et al. Asthma control in Europe: a real-world evaluation based on an international population-based study. J Allergy Clin Immuno/ 2007;120:360-7. http://dx.doi.org/10.1016/j.jaci.2007.09.019

3. Peters SP, Jones CA, Haselkorn T, et al. Real-world Evaluation of Asthma Control and Treatment (REACT): findings from a national Web-based survey. J Allergy Clin Immuno/ 2007;119:1454-61. http://dx.doi.org/10.1016/ j.jaci.2007.03.022

4. Global Strategy for Asthma Management and Prevention, Global Initiative for Asthma (GINA) 2007. Available from: http://www. ginasthma.org.

5. Humbert M, Holgate S, Boulet LP, Bousquet J. Asthma control or severity: that is the question. Allergy 2007;62:95-101. http://dx.doi.org/10.1111/j.13989995.2006.01308.x

6. Rabe KF, Adachi M, Lai CK, et al. Worldwide severity and control of asthma in children and adults: the global asthma insights and reality surveys. J Allergy Clin Immunol 2004;114:40-7. http://dx.doi.org/10.1016/j.jaci.2004.04.042

Mclvor RA, Boulet LP, FitzGerald JM, et al. Asthma control in Canada: no improvement since we last looked in 1999. Can Fam Physician 2007;53:673-7.

8. Carlton BG, Lucas DO, Ellis EF, et al. The status of asthma control and asthma prescribing practices in the United States: results of a large prospective asthma control survey of primary care practices. J Asthma 2005;42:529-35. http://dx.doi.org/10.1081/JAS-67000

9. Chapman KR, Boulet LP, Rea RM, Franssen E. Suboptimal asthma control: prevalence, detection and consequences in general practice. Eur Respir J 2008; 31:320-5. http://dx.doi.org/10.1183/09031936.00039707

10. Hasselgren $M$, Arne $M$, Lindahl A, et al. Estimated prevalences of respiratory symptoms, asthma and chronic obstructive pulmonary disease related to detection rate in primary health care. Scand J Prim Health Care 2001;19:54-7. http://dx.doi.org/10.1080/028134301300034701

11. Lisspers K, Stallberg B, Hasselgren $M$, et al. Organisation of asthma care in primary health care in Mid-Sweden. Prim Care Resp J 2005;14:147-53. http://dx.doi.org/10.1016/j.pcrj.2005.03.003

12. Stallberg $B$, Lisspers $K$, Hasselgren $M$, et al. Factors related to the level of severity of asthma in primary care. Respir Med 2007;101:2076-83. doi:10.1016/j.rmed.2007.05.016

13. Hasselgren M, Gustafsson D, Stallberg B, et al. Management, asthma control and quality of life in Swedish adolescents with asthma. Acta Paediatr 2005;94: 682-8. http://dx.doi.org/10.1080/08035250510025851

14. Levy ML. Guideline-defined asthma control: a challenge for primary care. Eur Respir J 2008;31:229-31. http://dx.doi.org/10.1183/09031936.00157507

15. Horne R, Price D, Cleland J, et al. Can asthma control be improved by understanding the patient's perspective? BMC Pulm Med 2007;7:8. http://dx.doi.org/10.1186/1471-2466-7-8

16. Dekhuijzen PN, Magnan A, Kneussl M. The ADMIT series - issues in inhalation therapy. 1) The goals of asthma treatment: can they be achieved? Prim Care 
Resp J 2007; 16:341-8. http://dx.doi.org/10.3132/pcrj.2007.00081

17. Revicki $D$, Weiss KB. Clinical assessment of asthma symptom control: review of current assessment instruments. J Asthma 2006;43:481-7. http://dx.doi.org/ 10.1080/02770900600619618

18. Lundback B, Dahl R. Assessment of asthma control and its impact on optimal treatment strategy. Allergy 2007;62:611-19. doi:10.1111/j.1398-9995. 2007.01399.x

19. Pharmaceutical Benefits Board in Sweden (LFN). Final report - review of medicines against asthma, COPD and coughs; 2007. Available from: http://www.Ifn.se.

20. Fish L, Lung CL. Adherence to asthma therapy. Ann Allergy Asthma Immunol 2001;86:24-30.

21. Gillisen A. Patient's adherence in asthma. J Physiol Pharmacol 2007;58 Suppl 5:205-22.

22. van der Molen T, Ostrem A, Stallberg B, et al. International Primary Care Respiratory Group (IPCRG) Guidelines: management of asthma. Prim Care Resp J 2006;15:35-47. http://dx.doi.org/10.1016/j.pcrj.2005.11.001

23. Janson C, de Marco R, Accordini S, et al. Changes in the use of anti-asthmatic medication in an international cohort. Eur Respir J 2005;26:1047-55. http://dx.doi.org/10.1183/09031936.05.00031905

24. Wandell PE, Gafvels C. Metabolic control and quality of data in medical records for subjects with type 2 diabetes in Swedish primary care: improvement between 1995 and 2001. Scand J Prim Health Care 2002;20:230-5. http://dx.doi.org/10.1080/028134302321004890

25. Kristiansson P, Bjorholt I, Siewert-Delle A, Svardsudd K. To what extent do patients in general practice reach guideline lipid-lowering treatment goals? Eur J Cardiovasc Prev Rehabil 2007;14:149-51. http://dx.doi.org/10.1097/ HJR.0b013e3280125485
26. Furberg $\mathrm{H}$, Lichtenstein $\mathrm{P}$, Pedersen $\mathrm{NL}$, et al. Cigarettes and oral snuff use in Sweden: Prevalence and transitions. Addiction 2006;101:1509-15. http://dx.doi.org/10.1111/j.1360-0443.2006.01550.x

27. Tomlinson JE, McMahon AD, Chaudhuri R, et al. Efficacy of low and high dose inhaled corticosteroid in smokers versus non-smokers with mild asthma. Thorax 2005;60:282-7. http://dx.doi.org/10.1136/thx.2004.033688

28. Yawn BP. Factors accounting for asthma variability: achieving optimal symptom control for individual patients. Prim Care Resp J 2008;17:138-47 http://dx.doi.org/10.3132/pcrj.2008.00004

29. The ENFUMOSA cross-sectional European multicentre study of the clinical phenotype of chronic severe asthma. European Network for Understanding Mechanisms of Severe Asthma. Eur Respir J 2003;22:470-7.

30. Schatz M, Clark S, Camargo CA, Jr. Sex differences in the presentation and course of asthma hospitalizations. Chest 2006;129:50-5. http://dx.doi.org/ 10.1378/chest.129.1.50

31. Laforest L, Van Ganse E, Devouassoux G, et al. Influence of patients' characteristics and disease management on asthma control. J Allergy Clin Immunol 2006;117:1404-10. http://dx.doi.org/10.1016/j.jaci.2006.03.007

32. Vermeire PA, Rabe KF, Soriano JB, Maier WC. Asthma control and differences in management practices across seven European countries. Respir Med 2002;96: 142-9. http://dx.doi.org/10.1053/rmed.2001.1241

33. Holgate ST, Price D, Valovirta E. Asthma out of control? A structured review of recent patient surveys. BMC Pulm Med 2006;6Suppl1:S2. http://dx.doi.org/ 10.1186/1471-2466-6-S1-S2

34. Boulet LP, Phillips R, O'Byrne P, Becker A. Evaluation of asthma control by physicians and patients: comparison with current guidelines. Can Respir $J 2002$; 9:417-23.

\section{Available online at http://www.thepcrj.org}

